\title{
New Generation Transparent LPCVD ZnO Electrodes for Enhanced Photocurrent in Micromorph Solar Cells and Modules
}

\author{
Laura Ding, Mathieu Boccard, Grégory Bugnon, Mustapha Benkhaira, Matthieu Despeisse, Fanny Sculati-Meillaud, \\ Sylvain Nicolay, Paolo A. Losio, Oliver Kluth, Perrine Carroy, Onur Caglar, and Christophe Ballif
}

\begin{abstract}
ZnO bilayer films were deposited by low-pressure chemical vapor deposition in a single process step by controlling the differential doping of the nucleation and bulk parts of the layers. The resulting $2-\mu \mathrm{m}$-thick films are characterized by low free-carrier absorption and electron mobility over $40 \mathrm{~cm}^{2} / \mathrm{Vs}$. They, therefore, combine high transparency in the infrared region and moderate sheet resistance that can be lowered below $20 \Omega / \mathrm{sq}$. These properties make $\mathrm{ZnO}$ bilayers ideal candidates as electrodes for the development of micromorph thin-film solar cells with enhanced photogenerated current. The potential of such bilayer front electrodes for a further power improvement and cost reduction of industrial micromorph tandem modules is currently investigated at Oerlikon Solar. The first experiments already show a promising gain in the bottom $\mu \mathrm{c}-\mathrm{Si}: \mathrm{H}$ cell photogenerated current compared with the current generated with modules deposited on standard uniformly doped $\mathrm{ZnO}$ single-layer front contacts.
\end{abstract}

Index Terms-Bilayer, low-pressure chemical vapor deposition (LPCVD), micromorph, zinc oxide.

\section{INTRODUCTION}

$\mathbf{L}$ OW-PRESSURE chemical vapor deposited boron-doped zinc oxide (LPCVD ZnO:B) has been established over the past decade as one of the reference transparent conductive oxide (TCO) electrode material for record thin-film silicon (TFS) solar cells [1], [2]. For the case of micromorph devices, i.e., tandem junctions of hydrogenated amorphous and microcrystalline silicon (a-Si:H and $\mu \mathrm{c}-\mathrm{Si}: \mathrm{H})$ cells, research goes on with objectives of maximizing the transparency of the front electrode, keeping light scattering strong and the total layer thickness below $2 \mu \mathrm{m}$. Such a strategy should fulfill both the requirements of reaching

Manuscript received July 12, 2011; revised July 21, 2011; accepted December 2, 2011. Date of publication January 4, 2012; date of current version March 16, 2012. This work was supported by the Swiss Federal Office of Energy under Grant 101191 and by the European Union Seventh Framework Programme under PEPPER Project under Grant 249782.

L. Ding, M. Boccard, G. Bugnon, M. Benkhaira, M. Despeisse, F. SculatiMeillaud, S. Nicolay, and C. Ballif are with the Laboratory of Photovoltaics and Thin Film Electronics, Institute of Microengineering, Ecole Polytechnique Fédérale de Lausanne, CH-2000 Neuchâtel, Switzerland (e-mail: laura. ding@epfl.ch; mathieu.boccard@epfl.ch; gregory.bugnon@epfl.ch; mustapha. benkhaira@epfl.ch; matthieu.despeisse@epfl.ch; fanny.sculati-meillaud@epfl. ch; sylvain.nicolay@epfl.ch; christophe.ballif@epfl.ch).

P. A. Losio, O. Kluth, P. Carroy, and O. Caglar are with Oerlikon Solar Ltd., CH-9477 Trubbach, Switzerland (e-mail: paolo.losio@oerlikon.com; Oliver Kluth@oerlikon.com; perrine.carroy@oerlikon.com; onur.caglar@oerlikon. com).

Color versions of one or more of the figures in this paper are available online at http://ieeexplore.ieee.org.

Digital Object Identifier 10.1109/JPHOTOV.2011.2179415 higher current photogeneration, which is a step toward higher efficiency and developing industrially scalable processes for costeffective module production. Increasing the transparency can be achieved by reducing the doping level usually applied to reach highly conductive $\mathrm{ZnO}: \mathrm{B}$. Indeed, the free-carrier absorption (FCA) observed in the red/near infrared is then decreased, but to the cost of an increase in the sheet resistance of the layer, over the typical $10-\Omega /$ sq value [3]. However, micromorph devices allow for a larger tolerance in the trade-off of transparency versus conductivity struggle of TCO design. In fact, tandem junctions generate less photocurrent, for a total higher $V_{\mathrm{Oc}}$ than their separated single-junction constituents. Therefore, they can accommodate electrodes with a higher sheet resistance [4]. Strong light-scattering ability is a natural characteristic of the LPCVD $\mathrm{ZnO}$ [5]: In standard deposition condition, the layer develops a self-nanotextured surface, in the form of pyramidal rough features. To enhance the surface roughness, one way is to grow the film thicker, which we want here to avoid as it would lead to larger material and time consumptions. Another solution is to reduce the doping level, until reaching a non-intentionally doped (n-i-d) $\mathrm{ZnO}$ layer. Indeed, introduction of extrinsic dopants is known to decrease the grain size and scattering power of the film. Eventually, we could modify the nucleation conditions in order to promote the growth of larger grains [6]. If a 2- $\mu \mathrm{m}$-thick $\mathrm{n}$-i-d $\mathrm{ZnO}$ layer is, apparently, the ideal candidate to maximize transparency and light scattering, its applicability to the module scale cannot be retained due to its sensitivity toward damp heat exposure that leads to dramatic increase in resistivity [7].

In this paper, we present a solution based on optimized $2-\mu \mathrm{m}$-thick LPCVD ZnO:B bilayers [8], [9], consisting in the combination of a thin highly doped nucleation layer, followed by a n-i-d or lowly doped bulk layer. This combination in one process step still benefits from the advantages of the LPCVD technique: High deposition rates (up to $50 \AA$ /s), high homogeneity over large areas, and low deposition temperatures. However, the resulting films are strongly light diffusing, with low FCA and they exhibit a significantly improved conduction compared with purely n-i-d layers. The bilayers approach will be proven here well adapted for the development of micromorph solar cells, at laboratory and industrial scales.

\section{EXPERIMENTAL METHODS}

$\mathrm{ZnO}$ bilayers are prepared using the LPCVD technique. Diethylzinc (DEZ, $\left.\mathrm{Zn}\left(\mathrm{C}_{2} \mathrm{H}_{6}\right)_{2}\right)$ and water $\left(\mathrm{H}_{2} \mathrm{O}\right)$ vapors are used 


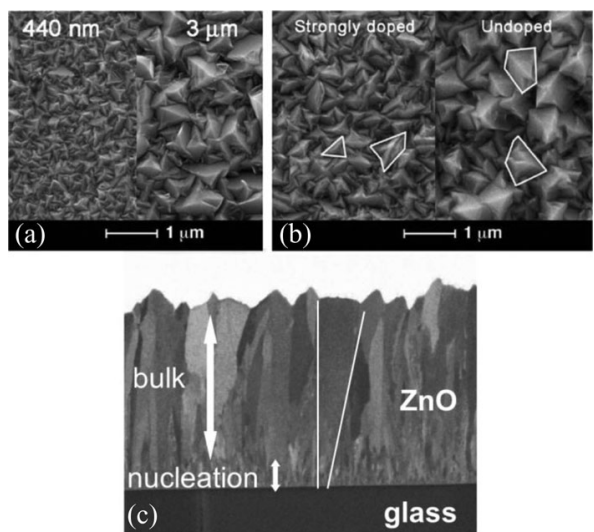

Fig. 1. SEM images of LPCVD ZnO, showing the evolution typical sharp pyramidal surface features with (a) the layer thickness and (b) with doping. (c) FIB-SEM cross section of a $1.8-\mu \mathrm{m}$-thick $\mathrm{ZnO}$ layer.

as precursors for $\mathrm{ZnO}$, and diborane diluted at $1 \%$ in argon $\left(\mathrm{Ar} / \mathrm{B}_{2} \mathrm{H}_{6}\right)$ is used as boron (B) dopant source. Further details on the deposition parameters can be found in [3]. The bilayers are formed in a single step by adapting only the $\mathrm{Ar} / \mathrm{B}_{2} \mathrm{H}_{6}$ flow into the gas mixture. The doping level is adjusted by varying the ratio of the $\mathrm{Ar} / \mathrm{B}_{2} \mathrm{H}_{6}$ flow over DEZ flow, which shall be denoted, here, as $\left[\mathrm{Ar} / \mathrm{B}_{2} \mathrm{H}_{6}\right] /[\mathrm{DEZ}]$. The layers presented here are typically $2-2.1 \mu \mathrm{m}$ thick. The bilayers are compared with two reference $\mathrm{ZnO}$ monolayers: $\mathrm{A}$ n-i-d $\mathrm{ZnO}$ and a homogeneously standard-doped $\mathrm{ZnO}$ film (Std), with $\left[\mathrm{Ar} / \mathrm{B}_{2} \mathrm{H}_{6}\right] /[\mathrm{DEZ}]=0.65$.

The $\mathrm{ZnO}$ films were characterized optically using a Perkin Elmer spectrophotometer (lambda 900) equipped with an integrating sphere, within a spectral range of $320-2000 \mathrm{~nm}$. The sheet resistance $R_{\mathrm{sq}}$ of the films was evaluated by a fourpoint probe measurement. An Ecopia Hall effect measurement system (HMS5000) was used to determine the Hall mobility $\mu_{\mathrm{H}}$, charge carrier density $N_{\mathrm{H}}$, and resistivity $\rho_{\mathrm{H}}$, using the Van der Pauw configuration, at room temperature. P-i-n micromorph devices were deposited on the $\mathrm{ZnO}$ electrode substrates by plasma-enhanced chemical vapor deposition (PECVD) in a KAI-S deposition reactor for the top a-Si:H cells, and in a research-scale system for the intermediate reflector and bottom $\mu \mathrm{c}-\mathrm{Si}$ :H cells [14], [15]. The cells were patterned to an area of $1 \mathrm{~cm}^{2}$. Their performances were characterized with currentvoltage measurements using an AM 1.5 Wacom sun simulator with $100-\mathrm{mW} / \mathrm{cm}^{2}$ light output, in standard conditions. The short-circuit current densities $J_{\mathrm{sc}}$ of both subcells were evaluated through spectral response measurements between 370 and $1100 \mathrm{~nm}$.

\section{Low-Pressure Chemical VAPor Deposited ZnO STRUCTURE AND PROPERTIES}

The surface morphology and grain structure of $\mathrm{ZnO}$ films with different thicknesses and doping levels are shown on scanning electron microscope (SEM) images and cross section focused ion beam (FIB)-SEM, in Fig. 1(a)-(c), respectively. LPCVD $\mathrm{ZnO}$ grows in standard temperature condition $\left(160^{\circ} \mathrm{C}\right)$ with the (11-20) crystallographic preferential orientation. The film evolves from a thin disordered nucleation layer, that expands over the first $\sim 400 \mathrm{~nm}$, to V-shape columnar grains that get larger in the bulk [see Fig. 1(c)]. Consecutively, as shown in Fig. 1(a), the grains develop tetragonal shaped tops that also enlarge with the layer thickness, conferring to the $\mathrm{ZnO}$ layers their rough light diffusive morphology. The same effect is also observed when the polycrystalline material is grown nonintentionally doped (n-i-d). As presented in Fig. 1(b), the grain structure is similar, but larger grains develop, which results in larger surface pyramids, scattering light more efficiently [5], [6].

Regarding the electrical conductivity of polycrystalline $\mathrm{ZnO}$, the charge carrier transport through the layer is known to be limited mainly by two phenomena: 1) Scattering at ionized impurities within the grains and 2) scattering at the grain boundaries (GBs) [10], [11]. N-i-d $\mathrm{ZnO}$ grows with large grains, resulting in a reduced GB density compared with doped $\mathrm{ZnO}$ of same thickness. However, the low free-carrier content of n-i-d films makes electron conduction very sensitive to GB scattering. Indeed, in the case of doped $\mathrm{ZnO}$, the additional free electrons resulting from extrinsic doping shrink the back-to-back Schottky potential barrier present at GB, facilitating transport via tunneling. Raising the doping level reduces the electron scattering at the GB, but at the same time increases intragrain impurity scattering.

By depositing $\mathrm{ZnO}$ bilayers instead of monolayers, the intention was to produce a layer that would exhibit the excellent light-scattering interface and low GB density of n-i-d $\mathrm{ZnO}$, while improving its conductivity. First, the effect of restraining B-dopant only in the nucleation part of the layer was investigated. The second step was dedicated to improve the electrical conductivity by tuning the bulk layer doping, while keeping a highly doped nucleation stage.

\section{INFLUENCE OF THE NUCLEATION DOPING}

It has been found that the thickness on which B-dopant is introduced ( $\mathrm{d}^{\text {doped }}$ ) has a decisive influence on the bulk growth, therefore on light scattering and electrical conductivity. Fig. 2 shows the optical effect when increasing the thickness of the B-doped layer thickness from $\mathrm{d}^{\text {doped }}=0$ (i.e., purely $\mathrm{n}$-i-d layer) to $2000 \mathrm{~nm}$ (corresponding to a Std layer). The doping level was adjusted to $\left[\mathrm{Ar} / \mathrm{B}_{2} \mathrm{H}_{6}\right] /[\mathrm{DEZ}]=0.65$.

As seen in Fig. 2(a), bilayers are significantly more transparent than the Std sample over the spectral range of absorption of both a-Si:H and $\mu \mathrm{c}-\mathrm{Si}: \mathrm{H}$. This already indicates that replacing a Std front electrode by a bilayer should lead to higher current photogeneration.

In addition, the light-scattering capability of the bilayers was assessed by evaluating their haze factor in transmission, as presented in Fig. 2(b). Here, the haze factor follows two different trends, with a clear divergence at $\mathrm{d}^{\text {doped }}=200 \mathrm{~nm}$. For $\mathrm{d}^{\text {doped }}>$ $200 \mathrm{~nm}$, the bilayers exhibit a light-scattering ability intermediate between the Std and the n-i-d, suggesting that those bilayers are characterized by larger grain and surface structures sizes than in the Std layer. This can be understood in terms of reduced doping that produces grains with sizes in between n-i-d and Std samples. However, for $\mathrm{d}^{\text {doped }}<200 \mathrm{~nm}$, the bilayers have a haze factor higher than the one of the Std, but also superior to 


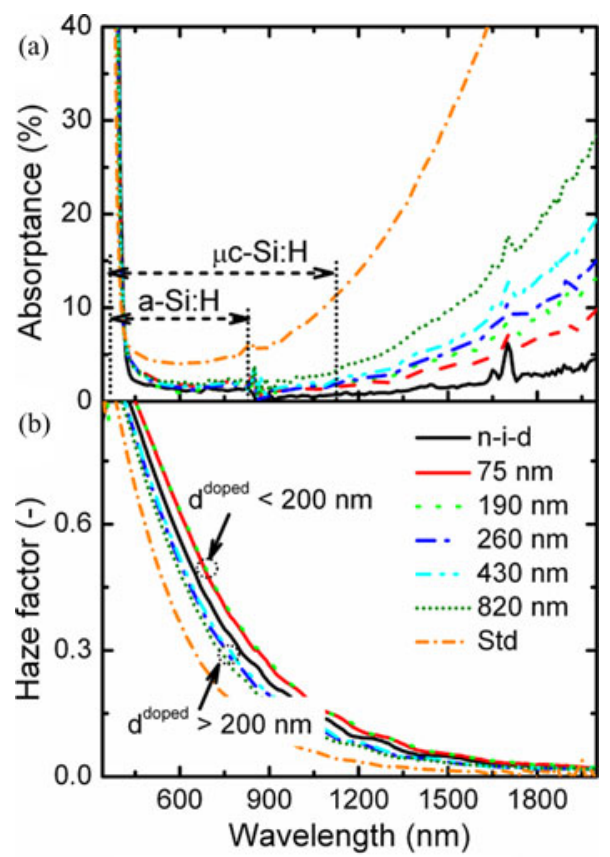

Fig. 2. (a) Absorptance spectra and (b) Haze factors in transmittance of $\mathrm{ZnO}$ bilayers and reference Std and n-i-d layers. The optical absorption ranges of $\mathrm{a}-\mathrm{Si}: \mathrm{H}$ and $\mu \mathrm{c}-\mathrm{Si}: \mathrm{H}$ solar cells are also displayed.

$\mathrm{n}$-i-d film. Hence, this indicates that the bilayers with dopant in the early nucleation stage, even though containing dopant, do have larger grain bulk structure and surface pyramidal features than n-i-d layers, for a similar thickness. These two apparently opposite results point toward a possible competition between two growth effects induced by the presence of boron atoms: Surfactant effect in the nucleation promoting larger grains [12] and a bulk grain lateral growth rate hindrance [13].

The electrical properties of the bilayers series are shown in Fig. 3. Despite low $N_{\mathrm{H}}$ and, therefore, weak screening of the potential barrier at $\mathrm{GB}$, the electron mobilities in the bilayers are astonishingly similar to the value in the Std sample, allowing a moderate sheet resistance between 20 and $40 \Omega /$ sq for the as-deposited bilayers. It is important to note, here, that bilayers benefit from an extra effect of improvement of their conductivity. Indeed, if the sheet resistance of a thin-doped layer $\mathrm{d}^{\text {doped }}<$ $200 \mathrm{~nm}\left(>10^{4} \Omega / \mathrm{sq}\right)$ would be combined to the sheet resistance value of $1.8-\mu \mathrm{m}$-thick $\mathrm{n}$-i-d layer ( $\sim 60 \Omega / \mathrm{sq})$, the resulting parallel combination would not match the value below $40 \Omega / \mathrm{sq}$. This suggests that $\mathrm{B}$ has, in this configuration, an enhanced effect in the decrease of the electron scattering at GB. Moreover, $\mu_{\mathrm{H}}$ presents a change in trend at $\mathrm{d}^{\mathrm{doped}}=200 \mathrm{~nm}$. Bilayers having $\mathrm{d}^{\text {doped }}<200 \mathrm{~nm}$ have $\mu_{\mathrm{H}}$ higher than the Std layer, whereas bilayers with $\mathrm{d}^{\text {doped }}>200 \mathrm{~nm}$ are either below or equal to $\mu_{\mathrm{H}}$ of Std. As for the haze factor, the Hall mobility is connected to the grain size, and, therefore, to GB density. So this reasonably confirms the suggestion that bilayers grown with $\mathrm{d}^{\text {doped }}$ smaller than $200 \mathrm{~nm}$ have larger grains than Std and even larger ones than n-i-d. Our hypothesis is that B might be able to diffuse from the pool of the thin-doped part into the bulk part, along the porous region of GB and not into the grains, allowing the

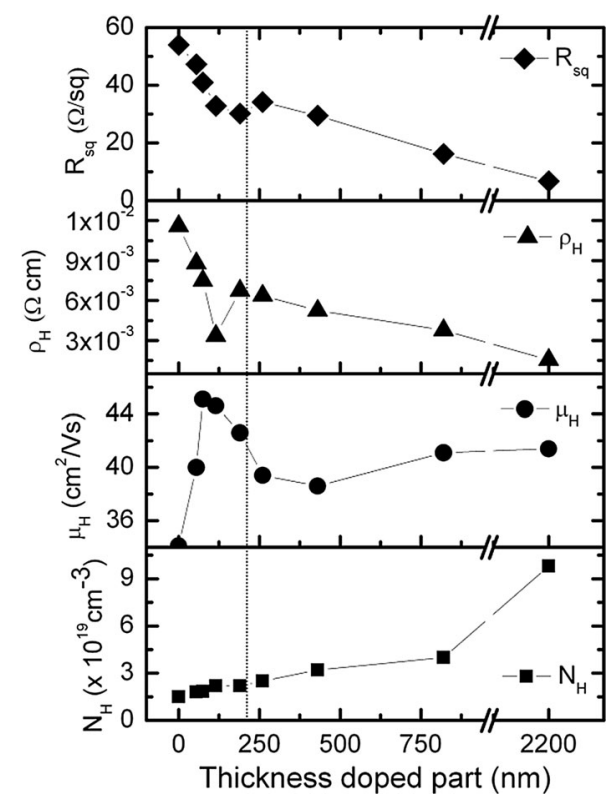

Fig. 3. Electrical properties of the bilayers as a function of the doped part thickness. The limit of 200-nm thickness is also displayed. The lines are guidelines for the eyes. $N_{\mathrm{H}}$ and $\mu_{\mathrm{H}}$ are taken as indicators of Hall mobility and carrier concentration, as the films are inhomogeneous in their thickness.

formation of a n-i-d-like layer, but with improved conductivity. Those B-induced growth and conduction enhancement effects are currently under further investigation.

\section{Bilayers With Doped BulK PART}

Starting from a bilayer structure with higher doping level restrained to a nucleation part thinner than $200 \mathrm{~nm}$, doping in the bulk part was investigated in order to further reduce the layer sheet resistance. This implies that the trade-off between transparency and conductivity was deliberately shifted toward lower film resistivity values in order to reach sheet resistance values under $20 \Omega /$ sq.

In this series, the $\left[\mathrm{Ar} / \mathrm{B}_{2} \mathrm{H}_{6}\right] /[\mathrm{DEZ}]$ ratios were fixed at 0.85 in the first 160-nm-thick-part and then varied from 0 to 0.3 in the bulk part of the layer.

As shown in Fig. 4(a), the absorptance of the bilayers increases with their bulk doping level, but stays significantly lower than in the Std layer, on the whole spectral range. The bilayer with the $\mathrm{n}$-i-d bulk $((0.85)+(0))$ is characterized by a higher haze factor than the $\mathrm{n}$-i-d, whereas the bilayers with the doped bulk part have their light scattering that diminishes with the doping level, as discussed in Section I. However, once again, they still diffuse more light than the Std.

The sheet resistance of the bilayers is effectively reduced with the increased bulk doping and free electron concentration, as shown in Table I. However, contrary to what was observed in the previous case, the mobility does not increase above the Std sample value.

As expected, by introducing a slight amount of dopant in the bulk part, bilayers sheet resistance was decreased below $20 \Omega /$ sq, while preserving the enhancement in light-scattering ability and transparency, compared with Std LPCVD ZnO front contact. 


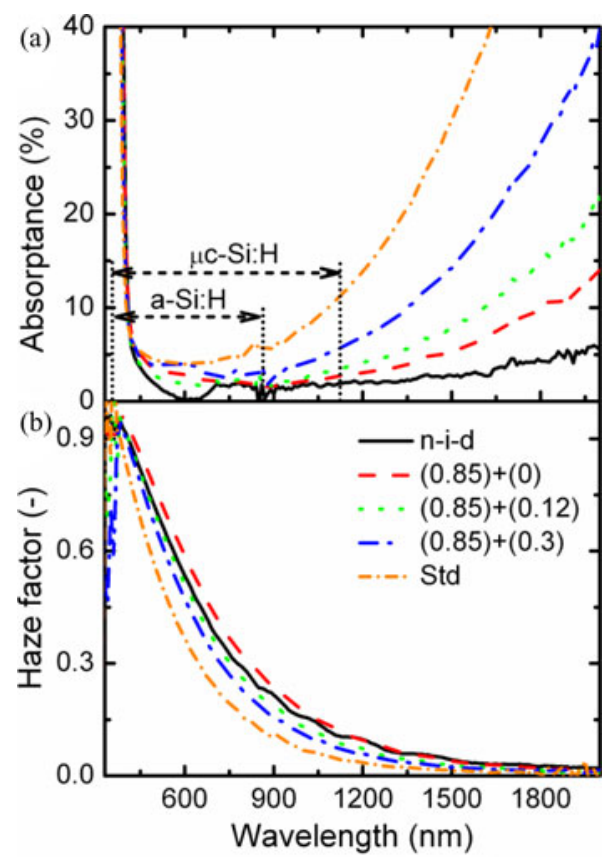

Fig. 4. (a) Absorptance spectra and (b) Haze factors in transmittance of $\mathrm{ZnO}$ bilayers with doped bulk and reference Std and n-i-d layers. Numbers in brackets correspond to the doping level in the nucleation and in the bulk part of the layers, respectively. The optical absorption ranges of a-Si:H and $\mu \mathrm{c}-\mathrm{Si}: \mathrm{H}$ solar cells are also displayed.

TABLE I

ELECTRICAL PROPERTIES OF THE BILAYERS WITH INCREASED DOPING LEVEL IN THE BULK PART AND ON THE STD LAYER

\begin{tabular}{lccc}
\hline \hline \multicolumn{1}{c}{ Sample } & $\mathrm{R}_{\mathrm{sq}}(\Omega / \mathrm{sq})$ & $\mu_{\mathrm{H}}\left(\mathrm{cm}^{2} /(\mathrm{Vs})\right)$ & $\mathrm{N}_{\mathrm{H}}\left(\times 10^{19} \mathrm{~cm}^{-3}\right)$ \\
\hline$(0.85)+(0)$ & 36.9 & 39.0 & 2.2 \\
$(0.85)+(0.12)$ & 18.2 & 42.2 & 3.9 \\
$(0.85)+(0.3)$ & 11.3 & 41.7 & 6.4 \\
Std & 8.7 & 40.2 & 9.8 \\
\hline \hline
\end{tabular}

\section{BILAYERS Front CONTACT FOR MicromorPh CELlS}

Finally, in order to test the suitability of the bilayers approach for TFS solar cells, a bilayer with n-i-d bulk and other bilayers with doped bulk were used as front contacts for micromorph solar cells, together with a Std doped layer as codeposited reference. The cells were deposited by PECVD, using very high frequency. They are constituted of 250-nm-thick top a-Si:H cell, 30-nm-silicon-oxide-based intermediate reflector grown in situ [14], and a $1500-\mathrm{nm}$-thick bottom $\mu \mathrm{c}-\mathrm{Si}: \mathrm{H}$ cell. Prior to deposition, the $\mathrm{ZnO}$ layer surfaces were lightly smoothed by argon plasma etching [15]. A lowly doped 5- $\mu$ m-thick $\mathrm{ZnO}$ was deposited as back contact and cells were patterned to an area of $1 \mathrm{~cm}^{2}$. As shown in Fig. 5, the micromorph cells deposited on the bilayers all generated more current particularly in the bottom cell compared with the cell on Std electrode. It can be seen that the current gain diminishes as doping in the bulk of the bilayers increases, which correlates well with the increased FCA and decreased haze factor.

Table II summarizes the cell performances. The fill factor (FF) and $V_{\text {oc }}$ drop originally observed on the bilayer having n-i-d bulk were partly recovered when the doping level was

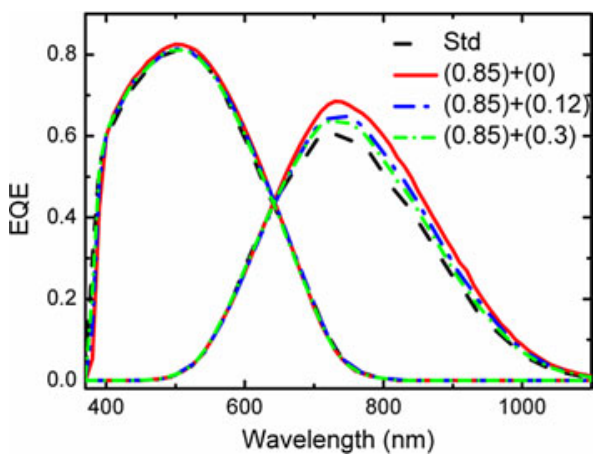

Fig. 5. External quantum efficiency of a $1-\mathrm{cm}^{2}$ micromorph cell deposited on bilayers and on a Std layer. Back contact is a lowly doped 5- $\mu$ m-thick $\mathrm{ZnO}$, and white paint was used as back reflector.

TABLE II

MicromorPh CELl PERFoRMANCES DEPOSITED ON ZnO BILAYERS WitH DIFFERENT DOPING AND ON A STD LAYER

\begin{tabular}{|c|c|c|c|c|c|}
\hline \multirow[b]{2}{*}{ Substrate } & \multicolumn{2}{|c|}{$\mathrm{J}_{\mathrm{sc}}\left(\mathrm{mA} / \mathrm{cm}^{2}\right)$} & \multirow[t]{2}{*}{ FF $(\%)$} & \multirow{2}{*}{$\begin{array}{l}\mathrm{V}_{\mathrm{oc}} \\
\text { (V) }\end{array}$} & \multirow{2}{*}{$\begin{array}{c}\eta \\
(\%)\end{array}$} \\
\hline & Top & Bottom & & & \\
\hline$(0.85)+(0)$ & 12.4 & 12.5 & 65.9 & 1.38 & 11.3 \\
\hline$(0.85)+(0.12)$ & 12.4 & 11.9 & 67.9 & 1.41 & 11.3 \\
\hline$(0.85)+(0.3)$ & 12.3 & 11.7 & 68.4 & 1.41 & 11.2 \\
\hline Std & 12.3 & 11.1 & 69.5 & 1.41 & 10.9 \\
\hline
\end{tabular}

increased in the bulk of the bilayers. However, apart form the electrode resistance, the FF loss can be ascribed to the current balance modification in the device, going from a strongly bottom limited configuration with the Std front contact to a more closely matched one on the bilayers.

Among the different bilayer options considered, the bilayer having moderate bulk doping of (0.12) seems to represent the optimum trade-off to guarantee both high current generation and cells electrical quality. This allowed us to achieve a higher initial efficiency on this bilayer substrate than on the Std reference.

\section{BILAYERS FOR MICROMORPH MODULES}

In the framework of the FP7 EU project PEPPER, the bilayer approach was tested at Oerlikon Solar (OS), as possible costeffective solution for front-electrode LPCVD ZnO layers to be used in micromorph modules. Indeed, the requirements of higher transparency for $R_{\mathrm{sq}}<20 \Omega / \mathrm{sq}$, as well as larger surface feature sizes with comparable or even lower layer thicknesses were all fulfilled by the bilayers with doped bulk part. In addition, the simple deposition process of the $\mathrm{ZnO}$ bilayers is compatible with inline deposition systems and very promising first results on $1.4-\mathrm{m}^{2}$-thin micromorph modules (220-nm top a-Si:H and 900-nm bottom $\mu \mathrm{c}$-Si:H cells) were obtained by including a bilayer front electrode (ATCO) instead of the classic-doped $\mathrm{ZnO}$ (STD_OS), as shown in Fig. 6. Practically, a net gain in the module current was already demonstrated thanks to bottom-cell current enhancement, proving the excellent industrial potential of bilayers. Together with further top-cell current improvement, the modules have potential for up to $3 \mathrm{~W}_{p}$ gain. 


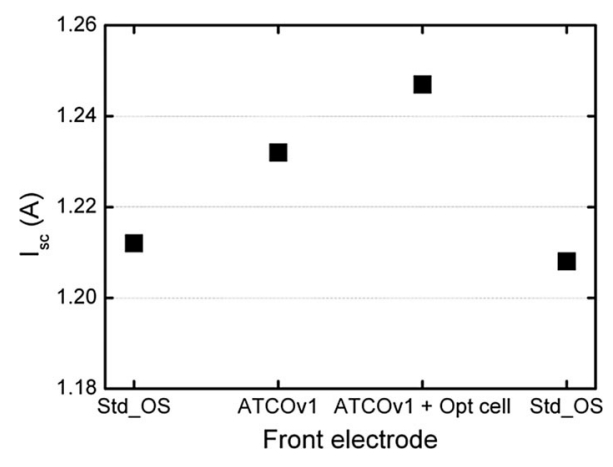

Fig. 6. Current $I_{\mathrm{sc}}$ of modules deposited on various electrodes at Oerlikon Solar: Std_OS is the standard doped electrode $1.8 \mu \mathrm{m}$, ATCOv1 is a bilayer, and ATCOv1 + Opt cell is a module on a bilayer with a bottom $\mu \mathrm{c}-\mathrm{Si}: \mathrm{H}$ cell optimized for higher current photogeneration. The current of the module on Std_OS is shown twice to illustrate the reproducibility of the process.

\section{CONCLUSION}

LPCVD bilayers were shown to combine higher transparency with the formation of larger $\mathrm{ZnO}$ grains compared with standard, uniformly doped. This enables stronger light scattering, as well as lower GB density. In addition, differential doping in the nucleation phase or in the bulk led to an enhanced reduction of the sheet resistance. This means that, for similar haze factor value and resistance as standard layers, the bilayer configuration allows the preparation of thinner films. The resulting layers demonstrated that they were promising electrodes not only for the development of micromorph solar cells at the lab level but at the production scale as well. Indeed, the simple one-step process is industrially scalable, making the bilayer approach an ideal candidate to push further the micromorph technology toward higher efficiencies and lower production costs.

\section{REFERENCES}

[1] S. Benagli, D. Borrello, E. Vallat-Sauvain, J. Meier, U. Kroll, J. Hotzel, J. Bailat, J. Steinhauser, M. Marmelo, G. Monteduro, and L. Castens, "High-efficiency amorphous silicon devices on LPCVD-ZnO TCO prepared in industrial KAI TM-M R\&D reactor," in Proc. 24th Eur. Photovoltaic Solar Energy Conf., Hamburg, Germany, 2009, pp. 21-25.

[2] J. Bailat, L. Fesquet, J.-B Orhan, B. Wolf, P. Madliger, J. Steinhauser, S. Benagli, D. Borello, L. Castens, G. Monteduro, M. Marmelo, B. Dehbozorghi, E. Vallat-Sauvain, X. Multone, D. Romang, J.-F. Boucher, J. Meier, U. Kroll, M. Despeisse, G. Bugnon, C. Ballif, S. Marjanovic, G. Kohnke, N. Borrelli, K. Koch, J. Liu, R. Modavis, D. Thelen, S. Vallon, A. Zakharian, and D. Weidman, "Recent developments of high-efficiency micromorph tandem solar cells in KAI-M PECVD reactors," in Proc. 25th Eur. Photovoltaic Solar Energy Conf., Valencia, Spain, 2010, pp. 27202723.

[3] S Faÿ, J. Steinhauser, N. Oliveira, E. Vallat-Sauvain, and C. Ballif, "Optoelectronic properties of rough LP-CVD ZnO:B for use as TCO in thin-film silicon solar cells," Thin Solid Films, vol. 515, pp. 8558-8561, 2007.

[4] J. Hanak, "Monolithic solar cell panel of amorphous silicon," Solar Energy, vol. 23, pp. 145-147, 1979.

[5] S. Faÿ, L. Feitknecht, R. Schlüchter, U. Kroll, E. Vallat-Sauvain, and A. Shah, "Rough ZnO layers by LP-CVD process and their effect in improving performances of amorphous and microcrystalline silicon solar cells," Solar Energy Mater. Solar Cells, vol. 90, pp. 2960-2967, 2006.

[6] S. Nicolay, S. Faÿ, and C. Ballif, "Growth model of MOCVD polycrystalline ZnO," Crystal Growth Design, vol. 9, pp. 4957-4962, 2009.

[7] J. Steinhauser, S. Faÿ, N. Oliveira, E. Vallat-Sauvain, D. Zimin, U. Kroll, and C. Ballif, "Electrical transport in boron-doped polycrystalline zinc oxide thin films," Phys. Status Solidi (a), vol. 205, pp. 1983-1987, 2008.
[8] L. Ding, S. Nicolay, G. Bugnon, M. Benkhaira, and C. Ballif, "Growth of LPCVD ZnO bilayers for solar cell front electrodes," in Proc. 25th Eur. Photovoltaic Solar Energy Conf., Valencia, Spain, 2010, pp. 2943-2946.

[9] L. Ding, M. Boccard, G. Bugnon, M. Benkhaira, S. Nicolay, M. Despeisse, F. Meillaud, and C. Ballif, "Highly transparent $\mathrm{ZnO}$ bilayers by LP-MOCVD as front electrodes for thin-film micromorph silicon solar cells," Solar Energy Mat. Solar Cells, 2012, doi:10.1016/j.solmat.2011.11.033, to be published.

[10] J. Y. W. Seto, "The electrical properties of polycrystalline silicon films," J. Appl. Phys., vol. 46, pp. 5247-5254, 1975.

[11] J. Steinhauser, S. Fä̈, N. Oliveira, E. Vallat-Sauvain, and C. Ballif, "Transition between grain boundary and intragrain scattering transport mechanisms in boron-doped zinc oxide thin films," Appl. Phys. Lett., vol. 90, pp. 142107-1-142107-3, 2007.

[12] M. L. Addonizio and C. Diletto, "Doping influence on intrinsic stress and carrier mobility of LP-MOCVD-deposited $\mathrm{ZnO}: \mathrm{B}$ thin films," Solar Energy Mater. Solar Cells, vol. 92, pp. 1488-1494, 2008.

[13] C. R. Wang, B. H. Müller, E. Bugiel, T. Wietler, M. Bierkandt, K. R. Hofmann, and P. Zaumseil, "Boron surfactant enhanced growth of thin $\mathrm{Si}$ films on CaF /Si," J. Vac. Sci. Technol. A, vol. 22, pp. 2246-2250, 2004.

[14] P. Buehlmann, J. Bailat, D. Dominé, A. Billet, F. Meillaud, A. Feltrin, and C. Ballif, "In situ silicon oxide based intermediate reflector for thin-film silicon micromorph solar cells," Appl. Phys. Lett., vol. 91, pp. 143505-1143505-3, 2007.

[15] J. Bailat, D. Domine, R. Schluchter, J. Steinhauser, S. Fay, F. Freitas, C. Bucher, L. Feitknecht, X. Niquille, T. Tscharner, A. Shah, and C. Ballif, "High-efficiency p-i-n microcrystalline and micromorph thin film silicon solar cells deposited on LPCVD ZnO coated glass substrates," in Proc. 4th World Conf. Photovoltaic Energy Convers., Waikoloa, HI, 2006, pp. 15331536.

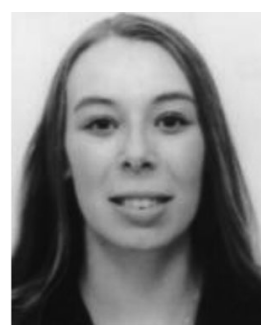

Laura Ding was born in Fribourg, Switzerland, on March 5, 1984. She received the M.Sc. degree in molecular and biological chemistry from the Ecole Polytechnique Federale de Lausanne (EPFL), Lausanne, Switzerland, in 2009. She is currently working toward the Ph.D. degree with the Laboratory of Photovoltaics and Thin Film Electronics, Institute of Microengineering, Neuchâtel, Switzerland.

Her main research interests include transparent conductive oxides and, in particular, zinc oxide, as the electrode for thin-film silicon solar cells.

Mathieu Boccard, photograph and biography not available at the time of publication.

Grégory Bugnon, photograph and biography not available at the time of publication.

Mustapha Benkhaira, photograph and biography not available at the time of publication. 
Matthieu Despeisse, photograph and biography not available at the time of publication.

Fanny Sculati-Meillaud, photograph and biography not available at the time of publication.

Sylvain Nicolay, photograph and biography not available at the time of publication.

Paolo A. Losio, photograph and biography not available at the time of publication.
Oliver Kluth, photograph and biography not available at the time of publication.

Perrine Carroy, photograph and biography not available at the time of publication.

Onur Caglar, photograph and biography not available at the time of publication

Christophe Ballif, photograph and biography not available at the time of publication. 